DOI: $10.17516 / 1998-2836-0163$

УДК 665.61:66.021.4

\title{
The Effect of Pre-Ozonation of Natural Bitumen on the Rate of Cracking Reactions
}

\author{
Nikita N. Sviridenko* and Anatoly K. Golovko \\ Institute of Petroleum Chemistry SB RAS \\ Tomsk, Russian Federation
}

Received 12.04.2019, received in revised form 26.11.2019, accepted 17.01.2020

\begin{abstract}
The effect of bitumen ozone-oxygen mixture pretreatment followed by cracking on thermolysis processes was investigated. Pretreatment of natural bitumen allowed to intensify the process of destruction of high-molecular components of raw materials, the content of which decreased by $8-15 \%$ wt. In the resulting liquid cracking products, oils predominate from 70 to $80 \% \mathrm{wt}$. Based on the formalized model of the thermal transformation of high-molecular components of the raw material, the rate constants of the bitumen thermolysis reactions $(\mathrm{k})$ and the effect of pretreatment of the ozoneoxygen bitumen mixture on the cracking reactions are calculated.
\end{abstract}

Keywords: natural bitumen, ozone, cracling, resins, asphaltenes.

Citation: Sviridenko N.N., Golovko A.K. The effect of pre-ozonation of natural bitumen on the rate of cracking reactions, J. Sib. Fed. Univ. Chem., 2020, 13(1), 78-88. DOI: 10.17516/1998-2836-0163

(c) Siberian Federal University. All rights reserved

This work is licensed under a Creative Commons Attribution-NonCommercial 4.0 International License (CC BY-NC 4.0).

* Corresponding author E-mail address: dark_elf26@mail.ru 


\title{
Влияние предварительной обработки озоном \\ природных битумов \\ на скорость протекающих реакций крекинга
}

\author{
Н.Н. Свириденко, А.К. Головко \\ Институт химии нефти СО РАН \\ Российская Федерация, Томск
}

\begin{abstract}
Аннотация. Исследован крекинг предварительно обработанных озоном природных битумов в различных условиях. Предварительная обработка природных битумов позволила интенсифицировать процесс деструкции высокомолекулярных компонентов сырья, содержание которых уменьшилось на 8-15 \% мас. В полученных жидких продуктах крекинга преобладают масла от 70 до 80 \% мас. На основании формализованной модели термического превращения высокомолекулярных компонентов сырья рассчитаны константы скоростей реакций термолиза битумов $(\mathrm{k})$ и определено влияние предварительной обработки озоно-кислородной смеси битумов на протекающие реакции крекинга.
\end{abstract}

Ключевые слова: природный битум, озон, крекинг, смолы, асфальтены.

Цитирование: Свириденко, Н.Н. Влияние предварительной обработки озоном природных битумов на скорость протекающих реакций крекинга / Н.Н. Свириденко, А.К. Головко // Журн. Сиб. федер. ун-та. Химия, 2020. 13(1). С. 7888. DOI: $10.17516 / 1998-2836-0163$

\section{Введение}

По мере истощения запасов легких и средних нефтей важным сырьевым источником для удовлетворения растущих потребностей в топливе становятся тяжелые высоковязкие нефти и природные битумы. Мировые ресурсы тяжелых нефтей и природных битумов значительно превышают запасы легких и оцениваются более чем в 810 млрд т [1]. Большими запасами природных битумов располагает Канада и Венесуэла, значительные запасы также имеет Мексика, США, Россия, Кувейт и Китай. По разным оценкам на территории Российской Федерации сосредоточено от 30 до 75 млрд т тяжелой нефти и природных битумов [1]. В настоящее время тяжелые нефти и битумы, как правило, первоначально подвергаются преобразованию в «синтетические» нефти, которые затем могут быть использованы для производства светлых нефтепродуктов, а также промышленных химических веществ [2]. Одной из основных проблем, связанных с переработкой тяжелого углеводородного сырья, является высокое содержание в его составе высокомолекулярных гетеросодержащих соединений - асфальтенов и смол, склонных к образованию кокса и отравлению катализаторов [3-6].

Для создания эффективных способов переработки тяжелых нефтей и природных битумов, а также дальнейшего использования полученных продуктов необходимы знания о влиянии температуры и природы катализаторов на различные функциональные группы в структуре молекул смол и асфальтенов [7-10]. Эти данные важны для более глубокого понимания измене- 
ний, которые происходят в смолах и асфальтенах в процессах термического и каталитического крекинга, выбора оптимальных схем модернизации установок и определения режимов переработки тяжелого углеводородного сырья нефтеперерабатывающими предприятиями [11-13].

Предполагалось, что протекающее в ходе предварительного озонирования раскрытие кольца многоядерных ароматических соединений битума в совокупности с последующим крекингом приведет к получению продуктов с более низкой молекулярной массой и улучшенной текучестью $[14,15]$. В работе [16] было показано, что предварительная обработка озоном выделенных из нефти асфальтенов способствует высокой их конверсии. Также было обнаружено снижение содержания ароматических соединений и их средней молекулярной массы после озонирования в сочетании с радиацией [17] или термическим крекингом тяжелой нефти [18, 19]. Известно, что озон активно взаимодействует с гетероорганическими соединениями сырья, это отражено в работах $[20,21]$. Показано, что предварительно обработка озоном способствует удалению серы из сырья. Однако изменение направленности протекающих реакций крекинга предварительно обработанных озоном тяжелых нефтяных объектов изучено недостаточно.

Целью данной работы являлось изучение влияния предварительной обработки озонокислородной смесью природных битумов с последующим крекингом на изменение направленности протекающих реакций, а также их скорости.

\section{Экспериментальная часть}

В качестве объектов исследования были выбраны битумы кармальского (КБ) и ашальчинского (АБ) месторождений, значительно различающиеся по своему химическому составу. Физико-химические характеристики битумов представлены в табл. 1.

Битум Ашальчинского месторождения характеризуется высокими значениями плотности - 978,1 кг/м³ - и вязкости - 1999,8 сСт, имеет значительное количество гетероатомов (7,49 \% мас.), основную часть которых составляет сера (4,74 \% мас.). Достаточно низкое значение $\mathrm{H} / \mathrm{C}=1,52$ указывает на то, что в составе данного битума содержится значительное количество циклических структур. Содержание смолисто-асфальтеновых компонентов 32,4 \% мас. Количество бензиновых фракций низкое $-4,6 \%$ мас. Содержание фракций 200-360 и 360-500 ${ }^{\circ} \mathrm{C}$ равно 27,9 и 41,6 \% мас. соответственно.

Битум Мордово-Кармальского месторождения также характеризуется высокими значени-

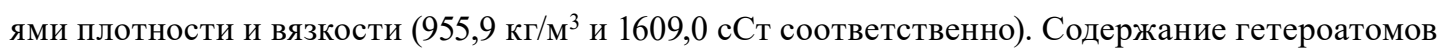
составляет более $7,1 \%$, из них количество серы - 3,65 \% мас. Отношение Н/С равно 1,72, что является достаточно высоким значением и свидетельствует о том, что в составе данного битума присутствует значительное количество алифатических соединений и фрагментов в молекулах насыщенных циклических соединений. Содержание масел в кармальском битуме больше (70,3 \% мас.), а сумма смолисто-асфальтеновых компонентов меньше, чем в ашальчинском битуме. Содержание бензиновых и дизельных фракций несколько выше (на 2,1 и 6,7 \% соответственно), чем в ашальчинском битуме, а фракций, выкипающих в интервале $360-500{ }^{\circ} \mathrm{C}$, ниже на $7,0 \%$ мас.

Исходные природные битумы обрабатывали озоно-кислородной смесью на лабораторной установке, оснащенной реактором барботажного типа, объемная скорость подачи газовой смеси 31,15 дм³/ч. Контроль за количеством поглощенного озона осуществляли на приборе 
Таблица 1. Физико-химические характеристики природных битумов

Table 1. Physico-chemical characteristics of the natural bitumen

\begin{tabular}{|c|c|c|}
\hline \multirow{2}{*}{ Показатели } & \multicolumn{2}{|c|}{ Природный битум } \\
\hline & Кармальский & Ашальчинский \\
\hline Плотность, кг/м ${ }^{3}$ & 955,9 & 978,1 \\
\hline Кинематическая вязкость, сСт & 1609,0 & 1999,8 \\
\hline \multicolumn{3}{|c|}{ Элементный состав, \% мас. } \\
\hline углерод & 81,20 & 82,10 \\
\hline водород & 11,62 & 10,41 \\
\hline кислород & 2,38 & 1,75 \\
\hline cepa & 3,65 & 4,74 \\
\hline азот & 1,15 & 1,00 \\
\hline $\mathrm{H} / \mathrm{C}$ & 1,72 & 1,52 \\
\hline \multicolumn{3}{|c|}{ Компонентный состав, \% мас. } \\
\hline масла & 70,3 & 67,6 \\
\hline смолы & 24,5 & 26,2 \\
\hline асфальтены & 5,2 & 6,2 \\
\hline \multicolumn{3}{|c|}{ Фракционный состав } \\
\hline нк, ${ }^{\circ} \mathrm{C}$ & 109 & 111 \\
\hline \multicolumn{3}{|c|}{ Выкипает, \% мас. } \\
\hline до $200^{\circ} \mathrm{C}$ & 6,7 & 4,6 \\
\hline $200-360^{\circ} \mathrm{C}$ & 34,6 & 27,9 \\
\hline $360-500^{\circ} \mathrm{C}$ & 34,6 & 41,6 \\
\hline
\end{tabular}

«Циклон 5.11». Роль метода заключается в избирательном поглощении озоном УФ-излучения с длиной волны 254 нм. Вследствие высокой вязкости озонирование битумов проводили при температуре $90{ }^{\circ} \mathrm{C}$. Количество озонокислородной смеси (1 г на 1 кг сырья) варьировало от 3 до 15 г/кг. Ранее проделанными работами было показано, что оптимальным количеством поглощенного озона для тяжелого углеводородного сырья с последующим крекингом является 6 г/кг [21].

Крекинг битумов в стационарном режиме проводили в автоклавах объемом $12 \mathrm{~cm}^{3}$. Масса битума, загружаемого в реактор, составляла 7 г. Эксперименты осуществляли в среде аргона при температурах 350, 400 и $450{ }^{\circ} \mathrm{C}$ и продолжительности от 60 до 120 мин.

Фракционный состав жидких продуктов крекинга устанавливали методом газожидкостной хроматографии на хроматографе «Кристалл-2000М» с пламенно-ионизационным детектором (ПИД), на кварцевой капиллярной колонке 25 м×0,22 мм со стационарной фазой $\mathrm{SE}-54$, газ-носитель - гелий. Хроматографирование шло в условиях линейного программирования температуры от 80 до $290{ }^{\circ} \mathrm{C}$ со скоростью нагрева термостата колонки $15{ }^{\circ} \mathrm{C} / \mathrm{Mин}$. Идентификацию углеводородов на хроматограммах проводили по временам удерживания н-алканов - гексана и гексадекана (внутреннего стандарта), а также характерного времени выхода пристана и фитана. Фракционный состав жидких продуктов крекинга определяли по методике, описанной в ГОСТ Р 56720-2015. 
Содержание смол и асфальтенов в природных битумах и в полученных жидких продуктах крекинга устанавливали по стандартной методике. Для выделения асфальтенов навеску образца разбавляли 40-кратным объемом гексана, выдерживали в течение суток и затем отфильтровывали выпавший осадок. Полученный осадок помещали в бумажный патрон и в аппарате Сокслета отмывали гексаном от соосажденных масел и смол, далее асфальтены вымывали хлороформом. Деасфальтенизированные образцы наносили на силикагель АСК, после чего последовательно экстрагировали в аппарате Сокслета углеводородные компоненты (масла) н-гексаном и смолы, выделяемые смесью бензол+этанол (1:1).

\section{Результаты и их обсуждение}

В табл. 2 представлен материальный баланс, вещественный и фракционный состав продуктов крекинга природных битумов в различных условиях. Видно, что при температурах ниже $450{ }^{\circ} \mathrm{C}$ реакции крекинга протекают медленно. Выходы побочных продуктов не превышают $2 \%$ мас., для КБ наблюдается увеличение содержания смол и снижение масел, тогда как для АБ обратная зависимость обратная. При температуре процесса $450{ }^{\circ} \mathrm{C}$ и продолжительности 60 минут для АБ в жидких продуктах крекинга возрастает выход масел на 1,7 \% и светлых фракций (НК-360 $\left.{ }^{\circ} \mathrm{C}\right)$ на $6,2 \%$ мас., в случае КБ выход светлых фракций составил $2,1 \%$, а со-

Таблица 2. Состав продуктов крекинга природных битумов

Table 2. Composition of natural bitumen cracking products

\begin{tabular}{|c|c|c|c|c|c|c|c|c|c|}
\hline \multirow{2}{*}{ Образец } & \multirow{2}{*}{$\mathrm{T}_{\text {н.к }},{ }^{\circ} \mathrm{C}$} & \multicolumn{3}{|c|}{ Фракционный состав, \% мас. } & \multicolumn{5}{|c|}{ Компонентный состав, \% мас. } \\
\hline & & нк-200 & $200-360$ & $>360$ & масла & смолы & $a^{*}$ & кокс & газ \\
\hline КБ (исх) & 111 & 6,7 & 34,6 & 58,7 & 70,3 & 24,5 & 5,2 & 0 & 0 \\
\hline АБ (исх) & 109 & 4,6 & 27,9 & 67,5 & 67,6 & 26,2 & 6,2 & 0 & 0 \\
\hline \multicolumn{10}{|c|}{ Крекинг $-350^{\circ} \mathrm{C}, 60$ мин } \\
\hline КБ & 123 & 5,5 & 37,0 & 57,0 & 65,9 & 28,0 & 5,6 & 0,4 & 0,1 \\
\hline АБ & 117 & 5,5 & 26,9 & 66,7 & 67,5 & 24,4 & 7,1 & 0,9 & 0,0 \\
\hline \multicolumn{10}{|c|}{ Крекинг - $400^{\circ} \mathrm{C}, 60$ мин } \\
\hline КБ & 115 & 6,0 & 35,0 & 58,1 & 68,1 & 25,8 & 5,1 & 0,5 & 0,4 \\
\hline АБ & 117 & 5,4 & 26,9 & 66,5 & 69,3 & 23,0 & 6,6 & 1,1 & 0,1 \\
\hline \multicolumn{10}{|c|}{ Крекинг - $450^{\circ} \mathrm{C}, 60$ мин } \\
\hline КБ & 128 & 6,5 & 36,9 & 55,0 & 66,2 & 27,4 & 4,8 & 1,0 & 0,6 \\
\hline АБ & 113 & 7,7 & 31,0 & 59,8 & 70,4 & 20,7 & 7,4 & 1,1 & 0,4 \\
\hline \multicolumn{10}{|c|}{ Крекинг $-450^{\circ} \mathrm{C}, 100$ мин } \\
\hline КБ & 74 & 12,7 & 39,4 & 44,1 & 72,9 & 17,9 & 5,4 & 2,0 & 1,8 \\
\hline АБ & 106 & 7,7 & 30,1 & 59,4 & 70,2 & 19,7 & 7,3 & 1,8 & 1,0 \\
\hline \multicolumn{10}{|c|}{ Крекинг $-450^{\circ} \mathrm{C}, 120$ мин } \\
\hline КБ & 72 & 16,7 & 32,7 & 30,2 & 65,4 & 11,6 & 2,8 & 6,2 & 14,2 \\
\hline АБ & 103 & 8,3 & 29,6 & 56,1 & 68,9 & 18,0 & 7,1 & 3,4 & 2,6 \\
\hline \multicolumn{10}{|c|}{ a*-асфальтены } \\
\hline
\end{tabular}


держание масел уменьшилось на 4,1 \% мас. Вероятно, реакции конденсации масел протекают несколько быстрее в этих условиях для КБ.

При продолжительности 100 мин реакции деструкции заметно ускоряются. Так, содержание смол и асфальтенов в жидких продуктах крекинга битумов снизилось на 4,4 и 5,4 \%, содержание масел и количество фракций, выкипающих до $360{ }^{\circ} \mathrm{C}$, увеличилось на 2,6 и 3,6 \% и на 10,8 и 5,3\% мас. для КБ и АБ соответственно.

Повышение времени процесса до 120 мин ускоряет реакции деструкции. Возрастает выход побочных продуктов, газа и кокса с 3,8 до 20,4 \% для КБ и с 2,8 до 6,0 \% мас. для АБ. Содержание масел, смол и асфальтенов при этом снижается на 7,5, 8,3 и 2,6 \% для КБ и на 1,3, 1,7 и 0,2 \% мас. для АБ в сравнении с крекингом при продолжительности 100 мин.

Основная идея использовать предварительную обработку озоном заключалась в высокой скорости взаимодействия озона с ароматическими соединениями, которые в составе битумов содержатся в значительном количестве [14]. На рис. 1 представлена схема взаимодействия озона с нафталином с образованием фталевой кислоты. Как показано авторами [14], обработка нафталина приводит к образованию ряда продуктов, которые при нагревании легче будут подвергаться деструкции.

В табл. 3 показаны результаты по крекингу предварительно обработанных озоном битумов. Как видно, при 60 мин крекинга предварительно обработанный КБ разрушается на 13,3 \% мас. больше смол и асфальтенов (табл. 2). Увеличение продолжительности крекинга до 100 мин способствует деструкции смол, содержание которых составило 10,0 \% мас., выход побочных продуктов равнялся 2,7 \%, что на $1,1 \%$ мас. меньше, чем при термокрекинге. В этих условиях замедляется газо- и коксообразование, тогда как выход масел максимален - 81,8 \% мас. При дальнейшем увеличении времени процесса до 120 мин по сравнению с крекингом не обработанного озоном КБ наблюдается замедление выхода газа и кокса на 17,4 \% мас., ускорение реакций деструкции с образованием масел (до 81,7 \%). Выход светлых фракций (нк- $360{ }^{\circ} \mathrm{C}$ ) составил 52,8 \% мас., что на 3,4 \% больше, чем при крекинге битума (табл. 2).

Таким образом, предварительная обработка озоном и последующий крекинг КБ способствуют замедлению реакций образования побочных продуктов (газа и кокса), увеличению выхода масел в составе жидких продуктов и фракций нк-360 ${ }^{\circ} \mathrm{C}$.

Для АБ предварительная обработка озоном с последующим крекингом привела к другим закономерностям по сравнению с КБ. Так, при 60 мин крекинга (табл. 3) реакции крекинга замедлились, это видно по меньшей деструкции смолисто-асфальтеновых компонентов, содержание которых составило 29,7 \%; это сказалось на меньшем выходе побочных продуктов

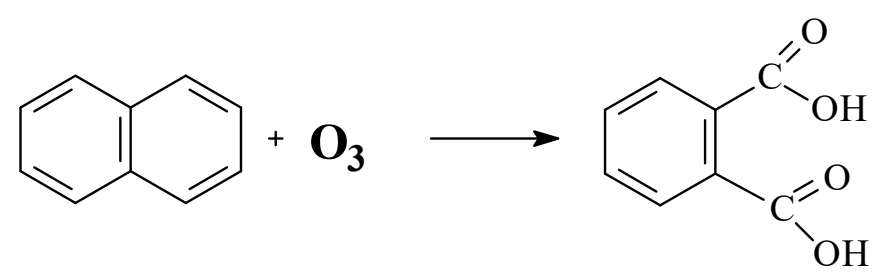

Рис. 1. Взаимодействие нафталина с озоном с образованием фталевой кислоты [14]

Fig. 1. The interaction of naphthalene with ozone with the formation of phthalic acid 
Таблица 3. Состав продуктов крекинга предварительно обработанных озоном природных битумов

Table 3. Composition of pre-ozonated natural bitumen cracking products

\begin{tabular}{|c|c|c|c|c|c|c|c|c|c|}
\hline \multirow{2}{*}{ Образец } & \multirow{2}{*}{$\mathrm{T}_{\text {н.к. }},{ }^{\circ} \mathrm{C}$} & \multicolumn{3}{|c|}{ Фракционный состав, \% мас. } & \multicolumn{5}{|c|}{ Компонентный состав, \% мас. } \\
\hline & & нк-200 & $200-360$ & $>360$ & масла & смолы & $a^{*}$ & кокс & газ \\
\hline КБ (исх) & 111 & 6,7 & 34,6 & 58,7 & 70,3 & 24,5 & 5,2 & 0 & 0 \\
\hline АБ (исх) & 109 & 4,6 & 27,9 & 67,5 & 67,6 & 26,2 & 6,2 & 0 & 0 \\
\hline \multicolumn{10}{|c|}{ Крекинг - $450{ }^{\circ} \mathrm{C}, 60$ мин } \\
\hline КБ & 85 & 7,5 & 36,1 & 54,3 & 79,0 & 13,5 & 5,4 & 1,6 & 0,5 \\
\hline АБ & 91 & 5,7 & 30,0 & 63,1 & 69,1 & 22,2 & 7,5 & 0,6 & 0,6 \\
\hline \multicolumn{10}{|c|}{ Крекинг $-450^{\circ} \mathrm{C}, 100$ мин } \\
\hline КБ & 76 & 12,7 & 39,1 & 45,5 & 81,8 & 10,0 & 5,5 & 1,9 & 0,8 \\
\hline АБ & 80 & 13,7 & 33,1 & 42,9 & 70,7 & 11,5 & 7,5 & 3,9 & 6,4 \\
\hline \multicolumn{10}{|c|}{ Крекинг - $450^{\circ} \mathrm{C}, 120$ мин } \\
\hline КБ & 70 & 15,3 & 37,5 & 44,2 & 81,7 & 9,5 & 5,8 & 1,9 & 1,1 \\
\hline АБ & 65 & 18,4 & 28,3 & 39,1 & 68,7 & 9,6 & 7,5 & 4,6 & 9,6 \\
\hline \multicolumn{10}{|c|}{ a* - асфальтены } \\
\hline
\end{tabular}

1,2 \% мас. Содержание бензиновых и дизельных фракций 35,9 \%, тогда как при крекинге этот показатель 38,7 \% мас. Однако при увеличении времени крекинга до 100 мин наблюдается ускорение реакций деструкции смол и асфальтенов на 13,4 и 8,0 \%, за счет чего возрастает выход светлых фракций на 14,3 и 9,0 \% мас. по сравнению с исходным битумом и термокрекингом соответственно. При этом выход побочных продуктов увеличивается с 2,8 до 10,3 \% мас. в сравнении с термокрекингом необработанного битума. Дальнейшее увеличение времени крекинга до 120 мин ускоряет нежелательные реакции: образование газа и кокса, снижение выхода масел и дизельной фракции в их составе.

Итак, предварительная обработка озоном с последующим крекингом изменяет направленность протекающих процессов крекинга. Вовлекается в процесс крекинга больше смол, что позволяет получать больше фракций нк-360 ${ }^{\circ} \mathrm{C}$.

Чтобы изучить влияние предварительной обработки озоном с последующим крекингом на изменение протекающих реакций, рассчитывали кинетические параметры процесса исходя из данных (табл. 2 и 3). При крекинге тяжелого углеводородного сырья протекают радикальноцепные реакции распада и конденсации (рис. 2). На основании литературных источников [22] и анализа полученных нами экспериментальных данных предложен механизм процесса термолиза. В данной схеме реакции $\mathrm{k}_{1}, \mathrm{k}_{3}, \mathrm{k}_{4}, \mathrm{k}_{6}, \mathrm{k}_{8}$ и $\mathrm{k}_{9}$ являются реакциями распада и образования из высокомолекулярных компонентов соединений с меньшей молекулярной массой, а реакции $\mathrm{k}_{2}, \mathrm{k}_{5}, \mathrm{k}_{7}$ и $\mathrm{k}_{10}$ - реакции поликонденсации. На основе предложенного формализованного механизма процесса термолиза была составлена кинетическая модель (рис. 3). При разработке кинетической модели необходимо оценить значения кинетических параметров, то есть кинетических констант. Оценка констант при различных условиях осуществлялась на основании полученных экспериментальных данных процесса термолиза методом прямого поиска. 


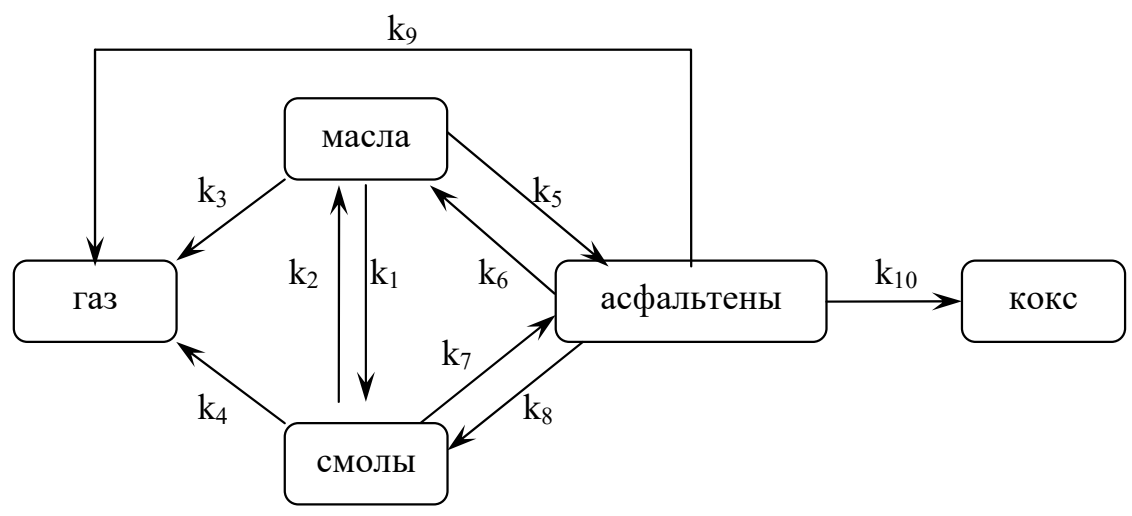

Рис. 2. Формализованная схема протекающих реакций крекинга

Fig. 2. Formalized scheme of proceeding cracking reactions

$$
\begin{aligned}
& \frac{d C_{\text {газ }}}{d t}=k_{3} C_{\text {масла }}+k_{4} C_{\text {смоль }}+k_{9} C_{\text {асфальтень }} \\
& \frac{d C_{\text {масла }}}{d t}=-k_{1} C_{\text {масла }}+k_{2} C_{\text {смоль }}-k_{3} C_{\text {масла }}-k_{5} C_{\text {масла }}+k_{6} C_{\text {асфальтень }} \\
& \frac{d C_{\text {смольь }}}{d t}=k_{1} C_{\text {масла }}-k_{2} C_{\text {смоль }}-k_{4} C_{\text {смоль }}-k_{7} C_{\text {смоль }}+k_{8} C_{\text {асфальтены }} \\
& \frac{d C_{\text {асфальтень }}}{d t}=k_{5} C_{\text {масла }}-k_{6} C_{\text {асфальтенье }}+k_{7} C_{\text {смоль }}-k_{8} C_{\text {асфальтены }}-k_{10} C_{\text {асфальтеньь }} \\
& \frac{d C_{\text {кокс }}}{d t}=k_{10} C_{\text {асфальтень }}
\end{aligned}
$$

Рис. 3. Кинетическая модель

Fig. 3. Kinetic model

Рассчитанные константы скоростей реакций крекинга без и с предварительной обработкой озоном битумов представлены в табл. 4. Из данных видно, что при крекинге предварительно обработанного озоном КБ замедляется реакция образования кокса, вследствие чего его выход снижается по сравнению с крекингом исходного битума. Это объясняется тем, что при деструкции продуктов озонирования увеличивается скорость реакций образования асфальтенов из смол и смол из асфальтенов, а также реакций образования масел из асфальтенов, тогда как при крекинге необработанного озоном битума эти реакции протекают медленно. Реакции газообразования замедляются. Газообразные продукты легче образуются из смол $\left(\mathrm{k}_{4}\right)$. Также замедляется реакция образования смол из масел, что обуславливает высокое содержание масел в составе жидких продуктов. При деструкции смол фрагменты попадают в масла.

В случае АБ реакции образования масел из смол (константа скорости $\mathrm{k}_{2}$ ) и кокса из асфальтенов (константа скорости $\mathrm{k}_{10}$ ), как и при крекинге не обработанного озоном битума, протекают наиболее быстро. При этом наблюдается ускорение деструкции масел с образо- 
Таблица 4. Эффективные константы скоростей реакций крекинга природных битумов

Table 4. Effective rate constants for cracking reactions of natural bitumen

\begin{tabular}{|c|c|c|c|c|}
\hline \multirow{2}{*}{$\begin{array}{c}\text { Константы } \\
\left.\text { скоростей (мин }{ }^{-1}\right)\end{array}$} & \multicolumn{2}{|c|}{ Крекинг КБ } & \multicolumn{2}{|c|}{ Крекинг АБ } \\
\hline & Исходного & $\mathrm{O}^{*}$ & Исходного & $\mathrm{O}^{*}$ \\
\hline $\mathrm{k}_{1}$ & $7,5 \cdot 10^{-4}$ & $1,0 \cdot 10^{-4}$ & $1,1 \cdot 10^{-4}$ & $3,5 \cdot 10^{-4}$ \\
\hline $\mathrm{k}_{2}$ & $7,5 \cdot 10^{-3}$ & $8,1 \cdot 10^{-3}$ & $6,0 \cdot 10^{-3}$ & $7,9 \cdot 10^{-3}$ \\
\hline $\mathrm{k}_{3}$ & $1,0 \cdot 10^{-3}$ & $8,5 \cdot 10^{-5}$ & $2,3 \cdot 10^{-4}$ & $8,0 \cdot 10^{-4}$ \\
\hline $\mathrm{k}_{4}$ & $3,0 \cdot 10^{-4}$ & $1,6 \cdot 10^{-4}$ & $3,4 \cdot 10^{-4}$ & $1,5 \cdot 10^{-4}$ \\
\hline $\mathrm{k}_{5}$ & $2,3 \cdot 10^{-4}$ & $2,0 \cdot 10^{-4}$ & $2,4 \cdot 10^{-4}$ & $6,1 \cdot 10^{-4}$ \\
\hline $\mathrm{k}_{6}$ & $2,0 \cdot 10^{-4}$ & $2,8 \cdot 10^{-4}$ & $1,8 \cdot 10^{-4}$ & $2,4 \cdot 10^{-4}$ \\
\hline $\mathrm{k}_{7}$ & $7,0 \cdot 10^{-4}$ & $4,0 \cdot 10^{-4}$ & $5,0 \cdot 10^{-4}$ & $9,0 \cdot 10^{-4}$ \\
\hline $\mathrm{k}_{8}$ & $2,1 \cdot 10^{-4}$ & $3,0 \cdot 10^{-4}$ & $2,0 \cdot 10^{-4}$ & $1,8 \cdot 10^{-4}$ \\
\hline $\mathrm{k}_{9}$ & $1,2 \cdot 10^{-4}$ & $8,0 \cdot 10^{-5}$ & $3,0 \cdot 10^{-5}$ & $1,3 \cdot 10^{-4}$ \\
\hline $\mathrm{k}_{10}$ & $8,5 \cdot 10^{-3}$ & $2,8 \cdot 10^{-3}$ & $4,1 \cdot 10^{-3}$ & $5,6 \cdot 10^{-3}$ \\
\hline \multicolumn{5}{|c|}{ О* - предварительно обработанного озоном } \\
\hline
\end{tabular}

ванием газообразных продуктов $\left(\mathrm{k}_{3}\right)$, вероятно, вследствие наличия в составе масел битума значительного количества гетероатомов и ароматических структур, которые активно взаимодействуют с озоном и при крекинге легче деструктируют. Именно особенности состава масел АБ обуславливают высокие выходы газообразных продуктов. Также наблюдается ускорение реакций конденсации компонентов масел и смол $\left(\mathrm{k}_{5}\right.$ и $\left.\mathrm{k}_{7}\right) \mathrm{c}$ образованием асфальтенов, а дополнительное количество вновь образованных асфальтенов способствует большему выходу кокса.

\section{Заключение}

Таким образом, установлено, что предварительная обработка озоном способствует увеличению глубины деструкции смолистых компонентов исходных битумов с образованием дополнительных количеств фракций, выкипающих до $360{ }^{\circ} \mathrm{C}$ по сравнению с термокрекингом. На основании эффективных констант скоростей реакции установлено влияние предварительной обработки озоном с последующим крекингом разных природных битумов на состав продуктов. Показано, что предварительная обработка озоном с последующим крекингом битумов ускоряет деструкцию ароматических ядер смол $\left(\mathrm{k}_{2}\right)$ и асфальтенов $\left(\mathrm{k}_{6}\right.$ и $\left.\mathrm{k}_{8}\right)$ с образованием компонентов меньшей молекулярной массы. Выявлено, что для природного битума с низким атомным отношением $\mathrm{H} / \mathrm{C}$ предварительная обработка озоно-кислородной смесью ускоряет реакции коксо- и газообразования $\left(\mathrm{k}_{9}\right.$ и $\left.\mathrm{k}_{10}\right)$ из асфальтенов.

\section{Список литературы / References}

1. Okunev A.G., Parkhomchuk E.V., Lysikov A.I., Parunin P.D., Semeikina V.S., Parmon V.N. Catalytic hydroprocessing of heavy oil feedstocks. Russ Chem Rev 2015. Vol. 9, P. 987-999.

2. Shahandeh H., Li Z., Modeling and Optimization of the Upgrading and Blending Operations of Oil Sands Bitumen. Energy \& Fuels 2016. Vol. 30, P. $5202-5213$.

$$
-86-
$$


3. Nassar N.N., Hassan A., Pereira-Almao P., Application of nanotechnology for heavy oil upgrading catalytic steam gasification-cracking of asphaltenes. Energy \& Fuels 2011. Vol. 25, P. 15661570.

4. Qing-Kun Liu, Yan Xu, Xue-Cai Tan, Pei-Qing Yuan et. al. Pyrolysis of Asphaltenes in Subcritical and Supercritical Water: Influence of H-Donation from Hydrocarbon Surroundings. Energy \& Fuels 2017. Vol. 30, P. 3620-3628.

5. Sviridenko N.N., Krivtsov E.B., Golovko A.K., Krivtsova N.I. Cracking of natural bitumen in the presence of nanosized powers Mo and CuO. Petroleum and Coal 2016. Vol. 58(7), P. 732-735.

6. Sodero A.C.R., Silva H.S., Level P.G., Bouyssiere B., Korb J-P., Carrie H., Alfarra A., Bégué D., Baraille I. Investigation of the Effect of Sulfur Heteroatom on Asphaltene Aggregation. Energy\& Fuels 2016. Vol. 30, P. 4758-4766.

7. Ortega García F.J. and Juárez E.J. Heavy Oil Hydrocracking on a Liquid Catalyst. Energy \& Fuels 2017. Vol. 31, P. 7995-8000.

8. Díaz M.C., Uguna C.N., Cheeseman B., Barker J., Snape C.E. Investigation of the Fluid Behavior of Asphaltenes and Toluene Insolubles by High-Temperature Proton Nuclear Magnetic Resonance and Rheometry and Their Application to Visbreaking. Energy Fuels 2016, Vol. 30(3), P. 2012-2020.

9. Hauser A., Humaidan F., Al-Rabiah H., Halabi M.A. Study on thermal cracking of Kuwaiti heavy oil (vacuum residue) and it's SARA fractions by NMR spectroscopy. Energy \& Fuels. 2014. Vol. 28, P. 4321-4332.

10. Zhang J.X., Zhou Y., Xu Y., Tian H.P., Research and Development of Novel Heavy Oil Catalytic Cracking Catalyst RCC-1. China petroleum processing \& petrochemical technology 2014. Vol. 16, P. 7-11.

11. Морозов М.А., Акимов А.С., Журавков С.П., Свириденко Н.Н., Золотухина Н.Ю., Головко А.К., Восмериков А.В., Федущак Т.А. Каталитические свойства порошков карбида вольфрама в процессе крекинга тяжелого углеводородного сырья. Известия Томского политехнического университета. Инжиниринг георесурсов 2017. Т. 328(8), C. 16-24 [Morozov M.A., Akimov A.S., Zhuravkov S.P., Zolotukhina N.Yu., Sviridenko N.N., Golovko A.K., Vosmerikov A.V., Fedushchak T.A. Catalytic properties of tungsten carbide powers in cracking heavy petroleum feedstock. Bulletin of the Tomsk Polytechnic University. Geo Assets Engineering 2017. Vol. 328(8), P. 16-24. (In Russ.)]

12. Meena M., Edward F. Hydroprocessing Catalysts Containing Noble Metals: Deactivation, Regeneration, Metals Reclamation, and Environment and Safety. Energy Fuels 2017. Vol. 31, P. $5711-5750$

13. Holda P., Jose L.P., Montoya de la Fuente J.A., Marcos M. Effect of Metal Loading in NiMo/ A12O3 Catalysts on Maya Vacuum Residue Hydrocracking. Energy Fuels 2017. Vol. 31, P. 4843-4850

14. Hendessi S., de Klerk A. Ozonation of Oilsands Bitumen. Energy Fuels 2016. Vol. 30, P. 89418951.

15. Patent 0292297 US. Hong P.K.A., Cha Z. Ozonation conversion of heavy hydrocarbons for resource recovery. Publ. Date. 7.11. 2013.

16. Cha Z. Ozonation of Canadian Athabasca asphaltene. Ph.D. thesis, University of Utah, Salt Lake City, UT, 2009. 
17. Zaykin Y.A., Zaykina R.F. Stimulation of radiation-thermal cracking of oil products by reactive ozone-containing mixtures. Radiation Physics and Chemistry 2004. Vol. 71, P. 475-478.

18. Ongarbayev Y.K., Golovko A.K., Krivtsov E.B., Imanbayev Y.I., Tileuberdi E., Tuleutaev B., Mansurov Z.A. Thermocatalytic cracking of the natural bitumens of Kazakhstan. Solid Fuel Chemistry 2016. Vol. 50(2), P. 81-87.

19. Likhterova N.M., Lunin V.V., Torkhovskii V.N., Fionov A.V., Kollin A. Transformations of the components of heavy petroleum feedstock by ozone. Chem. Technol. Fuels Oils 2004. Vol. 40, P. $248-255$.

20. Likhterova N.M., Torkhovskii V.N., Frantsuzov V.K., Kirillova O.I., Lunin V.V. Chemical activation of diesel fractions with ozone for the hydrotreatment process. Petroleum chemistry 2005. Vol. 45(1), P. 1-10.

21. Свириденко Н.Н., Кривцов Е.Б., Головко А.К. Инициированный крекинг природного битума для увеличения выхода дистиллятных фракций. Известия Томского политехнического университета 2013. T. 323(3), C. 37-41. [Sviridenko N.N., Krivtsov E.B., Golovko A.K. Initiated cracking of natural bitumen to increase the yield of distillate fractions. Bulletin of Tomsk Polytechnic University 2013. Vol. 323(3), P. 52-58. (In Russ.)]

22. Dmitriev D.E., Golovko A.K. Transformations of resins and asphaltenes during the thermal treatment of heavy oils. Petroleum Chemistry 2010. Vol. 50 (2), P. 106-113. 